\title{
In Defense of a Hybrid Model for EFL Vocabulary Instruction
}

\author{
Gholam-Reza Abbasian \\ Imam Ali \& IA universities (South Tehran Branch), Iran \\ Banafsheh Arianezhad \\ Islamic Azad University, Garmsar Branch, Iran
}

\begin{abstract}
Vocabulary instruction has been tackled from various perspectives mainly in the form of taking the advantages of Vocabulary Learning Strategies (VLSs), but few validation and verification efforts are traceable in the literature. To fill the gap, this study was an attempt to validate, and then verify the feasibility of a hybrid model against lexical inferencing strategy on the retention rate of Iranian EFL learners. Sixty homogeneous students from different intact classes participated in these studies, who were exposed to treatments. Having received a diagnostic vocabulary pre-test, one group was exposed to infertencing-based strategy, while another received instruction in the form of multiple visualizations called characterized a Hybrid Model. In addition to the statistical analyses on test validation procedures, Leven's test verified the similar variances between two experimental groups prior to then treatments. However, the results of post-test pointed out that, though both groups had significant progress, the Hybrid Model group outperformed the lexical inferencing group not only in achievement but in retention power of the vocabulary items.
\end{abstract}

Index Terms - concept map, inferencing, vocabulary retention, vocabulary instruction

\section{INTRODUCTION}

Both declarative and procedural knowledge of vocabulary is the greatest tools that the teachers can give students not only in their education but more generally in life (Pikulski \& Templeton, 2004) and our ability to function in today's complex social and economic world is mightily affected by our language skills and word knowledge. Rupley, Logan and Nichols stated: "Vocabulary is the glue that holds stories, ideas and content together...making comprehension accessible for children" (Sedita, 2005) as she also reported high correlation word knowledge and reading comprehension.

Different researchers have researched and discussed on the importance of vocabulary in SLA and L2 methodology. To this end, Barcroft (2004) defined three points that underline the importance of vocabulary in SLAincluding: "(1) the relationship between vocabulary and the ability to communicate, (2) student perceptions about the relative importance of vocabulary, and (3) the critical role of vocabulary knowledge in the development of grammatical competence" (p.201).

\section{REVIEW OF RELATED LITERATURE}

\section{A. Vocabulary Learning and Teaching}

Vocabulary development process is unique in that according to Reider (2003) psychological dimensions of learning, such as implicit and explicit focused on other skills and components are debatable as to vocabulary acquisition. Such a confusing and blurred atmosphere has brought about introducing diverse terminologies including 'incidental' vs. 'intentional' learning, 'attended' vs. 'unattended' learning, or 'implicit' acquisition vs. 'explicit' directed learning. however, vocabulary, like any other skills and components of language, has been subject to variety of learning and thereby teaching mechanisms primarily including:

Incidental Vocabulary Learning (Nag, Herman\& Anderson, 1985);

Direct instruction (Laufer, 2009);

Indirect instruction (NICHD, 2000; Lauer, 2009, \&Krashen, 1989).

Incidental vocabulary leaning (Barcroft, 2004; Read 2004; Hulstijn et al., 1996; Guo,2010);

Intentional vocabulary learning (Barcroft, 2004; Guo, 2010; Ellis, 2005; Harmon, 1998; Laufer \& Hulstijn, 2001a);

\section{B. Effective Vocabulary Instruction}

Using different instructional activities to expand the vocabulary of students is emphasized by educational researchers. For example, Beck and Mckeown (1991) distinguished four major positions in this field (as cited in Fukkink and Glopper, 1998). The first insists on direct instruction in word meaning. The proponents of second position emphasize on wide reading as an important source for vocabulary learning. The advocates of third position stress that intrinsic complexity of deciphering the meaning of unknown words and encourage students to look up their meanings in a dictionary. The fourth position is a synthesis of the second and third position (cited in Fukkink and Glopper, 1998). 
Meanwhile, Blachowicz and Fisher (2009) identified five guidelines for effective vocabulary instruction including: (a) building a word-rich environment to develop learners' consciousness; (b) developing independent vocabulary learning strategies;(c) using instructional strategies that promote effective teaching and model good word-learning behaviors;(d) developing general vocabulary through scaffold wide reading, writing, and discussion;(e) using assessment that matches the goal of instruction.

Over-viewing current vocabulary studies, Schmitt (2008) summarized the facilitating factors in vocabulary instruction including increased: a) frequency of exposure; b) attention; c) noticing ; d) intention; e) a requirement to learn (by teacher, test, syllabus); f) use (for task or for a personal goal); g) manipulation; h) engagement time (a notion suggested by Mason \& Krashen, 2004, too), and i) interaction on the lexical item. Overall, he believed that anything that leads to more exposure, attention, manipulation, or time spent on lexical items furthers the instruction.

\section{Main Approaches and Areas of Vocabulary Instruction}

Coady (as cited in Barcroft, 2004) explained that there are widely varying number of approaches, methods and techniques about vocabulary learning or acquisition. Barcroft (2004) referred to Coady's work and presented ten major areas in vocabulary learning, but first six areas of them relate to vocabulary learning. He indicated that these six areas are points along incidental and intentional vocabulary learning. The last four areas of research on L2 vocabulary in his table involve other issues related to L2 vocabulary learning. Here the list of different areas in learning vocabulary and their findings is presented. This list is summarized of Barcroft's research (2004, pp. 201-202):

(1) Incidental Vocabulary Learning, (2)Lexical requirement for comprehension, (3) Input Enhancement and TextBased factors, (4) Vocabulary learning strategy, (5) Combined Indirect and Direct Vocabulary Instruction, (6) Methods of direct instruction, (7)Word-Based Determinants of Learnability, (8) Bilingual mental lexicon,( 9) Receptive versus productive vocabulary knowledge, and (10) Lexical Input Processing.

\section{Relationship between Vocabulary Instruction and VLSS}

Kuhn and Stahl (1998) stated that measures of word meanings correlate highly with measures of reading comprehension in general. In addition, Nagy, et al. (1985) stated that knowledge of specific word meanings in a passage is an excellent predictor of how well a person will read that passage. Harley (as cited in Tumolo, 2007) uttered "The relationship of vocabulary knowledge and reading has been a growing area of research. It has been described as a relationship of reciprocal causation". Also, Nation (2001) asserted that vocabulary knowledge and reading comprehension are closely and bidirectionally related. Tumolo (2007) referred to Eskey's model on vocabulary learning which is an interactive model between reading and vocabulary and considers two kinds of processing during reading. These two kinds are called top-down and bottom-up processing. In this model vocabulary knowledge is considered essential, since bottomup processing contributes to reading comprehension.

According to Takač (2008), two directions of research influence on research into vocabulary learning strategies. First one is research of general language learning strategies which showed that many of the learning strategies used by learners are in fact VLSs or maybe used in vocabulary learning. The second one is rooted in exploring the effectiveness of individual strategy application in vocabulary learning. Takač (2008, p.59) made an elaboration on VLSs integrated into reading and offered list of such strategies such as: (1) Dictionary Use; (2) Repetition or Memorization, which contains Repetition, Simple Word Rehearsal, Writing Word and Meaning, and Cumulative Rehearsal; (3) Mnemonic Devices, which contains Verbal mnemonic, Visual mnemonic, and Mixed mnemonics; (4) Rote Learning Strategy; (5) Marginal Gloss; (6) Guessing Method; and (7) Graphic Organizers.

\section{E. Selected Strategies of Vocabulary Instruction}

Interest in learning strategies first developed in the 1970s. It is commonly believed that when using Vocabulary Learning Strategies (VLS), learners initially analyze vocabulary learning tasks, subsequently plan, and monitor and evaluate their learning behaviors. Nowadays, researchers believe that successful language learners apply a variety of learning strategies and perform autonomously. Some prevalent and closely pertinent to the present study as briefly addressed here as follows:

Graphic Organizers

They have been used as an instructional activities for a long time that visually present new words while providing students with the opportunity to compare and contrast these new items to already learned words (as cited by Taylor, Mraz, Nichols, Richelman\&Wood, 2009). Also they consider Graphic Organizers as tools for increasing students’ vocabulary knowledge and incorporating many guidelines for the active processing of vocabulary. Nesbit (2006) uttered that graphic organizers and concept maps have some shared features and are used in similar ways, so graphic organizer research is relevant to analyzing the effects of concept maps. These properties are: 1) Dual coding and conjoint retention, 2) Verbal coding, 3) Learning strategy, 4) Individual differences, and 5) Collaborative and cooperative learning. According to Guastello, Beasley, and Sinatra (as cited in Taylor et al., 2009) graphic organizers have various formats but their use can provide readers with the structure and organization necessary to make difficult and complex concepts more comprehensible. Following two formats are discussed because of their applications in hybrid model.

Concept of Definition Map 
A variation of semantic mapping is a strategy that Schwartz and Raphael (1985) devised to help students acquire a concept of definition. This, too, is an explicit instruction strategies based on focusing the students to consider three questions about a concept they are studying: (1) what is it? (2) what is it like? (3) what are some examples? Schwartz and Raphael (1985) also claimed that concept of definition map instruction creates a condition that students gain control of the vocabulary acquisition process and act autonomously. Stahl and Shiel's (1992) idea as productive approach orientation, Blachowicz's (2009) view as dictionary-based strategy, Gouveia's (2004) look as multiple-perspective model, Ajideh's (as cited in King, 2011) notion as Socio-Constructivist and Schema Interactive are among many others beliefs that strongly support the applicability and effectiveness of Concept Definition Map strategy.

\section{Frayer Model}

The Frayer model (Frayer, Frederick, and Klausmeier, 1969) helps students learn new concepts through the use of attributes and non-attributes. It is recommended for very important and probably new and complex words only (Greenwood, 2010). Frayer et al. (1965) tried to use concept based on Bourne's definition, claiming that "a concept exists whenever two or more distinguishable objects or events have been grouped or classified together and set apart from objects on the basis of some common feature or property of each".

Mix Models of Visualizations

Nagy (1992) stated that the approaches that teach words in semantic field are more productive than the other approaches because the teaching of a tiny numbers of words serves as a spring board for teaching sets of related words (as cited in Stahl and Shiel, 1992). Eppler (2006) phrased that there are various types of mapping but each of them has some problems. Thus, he proposed using a mix mode or hybrid form of visualizations. Hybrid forms would combine the strong points of different visualizations to create a more flexible and powerful model. He believed that hybrid formats foster the visual literacy of students and the learners would be able to use them beside the ready- made visualization techniques to learning tasks.

Lexical Inferencing Strategy

Nassaji (2006) defined Lexical Inferencing strategies as any cognitive and meta-cognitive activity that learners use to drive the meaning of unknown words. Then, he categorized these strategies as identifying, evaluating, and monitoring strategies. Its usefulness has also been asserted by Pulido (2007) and de Bot et al (1997). Different researchers stated that inferencing is one of the central cognitive processes in reading comprehension (as cited in Nassaji, 2006). He (2006) also stated that inferencing happens at all the reading comprehension processes, ranging from integrating the text with background knowledge, to connecting the different parts of the text together, to linking known to unknown elements in the text and these processes involve prediction and interpretation of the text for meaning.

\section{FocUS OF THIS STUDY}

In this study, a hybrid model made of a combination of "concept definition map", Harmon's list (Harmon, 1998), and "frayer model" and multiple visualizations model was investigated as a strategy of vocabulary instruction. Given the merits and demerits of the strategies mentioned and the elements reported in the literature, and the problems associated with the Frayer model, concept definition map, the word map (Rosenbaum, 2001), conduct of this study as a verification of an integrative model for vocabulary instruction and learning is warranted on the grounds that each of the models individually suffers from certain deficiencies.

Rosenbaum (2001) explained some benefits of word map including:

- manipulation of prefixes

- structural analysis and morphology

- completing unique expression, and

- sentence writing

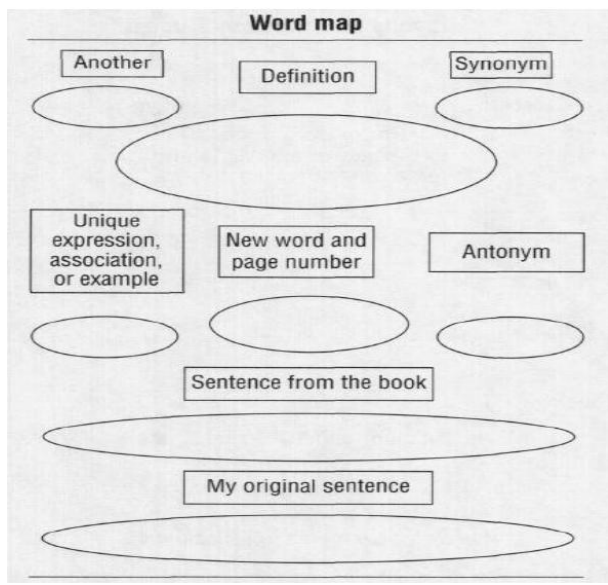

Figure 1: Word map (copied from Rosenbaum, 2001)

This hybrid model was compared with a modification of vocabulary inferencing strategy which is called reading plus. 
Wesche and Paribakht $(1998,2000)$ revealed that knowledge gains from reading followed by comprehension tasks are limited more to word-form familiarity or recognition knowledge of new words but the tasks entail manipulation of target words which first introduced in reading promoted retention of other aspects of word knowledge. Wesche and Paribakht's (2000) work has been guided by an input processing perspective on vocabulary development and it was a Reading plus introspective study. Through reading plus treatment, after reading the core text by learners, they carried out the eight text- based exercises.

The prominent aspect of this study is comparatively investigated the efficacy of lexical inferencing and the mixed model entitled here a Hybrid Model on the process of learner's retention rate. In fact, an integration of various strategies analogous to the Eclecticism in teaching methodology was procedurally implemented.

\section{Purposes OF THE STUdY}

To meet the purposes of this study and tackle the problem, the following research questions and hypotheses were raised:

1. Does the Lexical Inferencing have any significant impact on vocabulary retention rate?

2. Does the Hybrid Model have any significant impact on vocabulary retention rate?

3. Is the Hybrid Model more effective than the Lexical Inferencing in developing EFL learner's vocabulary retention rate?

\section{METHOD}

\section{A. Participants}

The main participants of this study were 60Iranian intermediate EFL learners selected based on a version of PET out of first 150, then out of the 100 homogeneous who were recruited for test piloting and any other procedural operations. The final group $(\mathrm{N}=60)$, was divided into two equal experimental groups in number.

\section{B. Materials}

\section{Text and Lexical Item Selecting}

Since strategy use within reading was the approach behind vocabulary instruction, simplicity and topic familiarity were two major principles for choosing the texts. Based on these principles, nine texts were chosen and their readability was computed through the Flesch reading ease andSMOG (a formula for secondary age $-4^{\text {th }}$ grades to college readers). The results of Flesch reading ease of texts were 58 to 67 that accorded standard level of texts. The texts were presented to piloting group and they tried to write the new words in a separate paper. After investigating the unknown words by the researcher, sixty four unknown words enjoying the highest frequency were included in the pre-test.

\section{Test Preparation}

A researcher-made multiple-choice test accommodating sixtylexical items was prepared, and then administered .A post-test composed of various subtests including the following formats was also developed for final achievement purposes.

- Matching items

- Sentence completion

- Synonym/definition

- Translation/equivalence

\section{PRoCEDURES}

As a quasi-experimental study in design, this study was procedurally conducted through the following steps:

\section{A. Experimental 1: Hybrid Instruction Group.}

The group experienced the following treatment steps:

\section{Pre-treatment phase:}

- Administration of the pre-test for diagnostic purpose

- Resort to dictionary when required

- Delivery of three simple and short texts and a sample of word map (pre-treatment stage)

- Certain activities to activate the participant's schemata

Treatment phase:

- Delivering of a copy of empty Word map

- Instructing to draw Word map

- Completing the word map

- Encouraging pair-work

- Checking the tasks and feed backing by teacher 
- Working on Nine texts including the target vocabulary items

- Treating the texts individually/in pairs to lookup the target words

- Putting the new word in the central bubble

- Recording the context in the elongated bubble

- Copying the essential parts of the context sentence

- Recording word definition/acronyms/synonym/ antonym/ etc in the small bubbles

- Finding part of speech to putting upper-left bubble

- Encouraging mutual consult

- Writing then independent and appropriate sentences

- Administering the Post-test

B. Experimental 2: Inferencing Group.

Pre-treatment phase: Repetition of the similar steps like those of the Hybrid Model

Treatment phase:

- instruction on using the roots and affixes, analyzing the structure

- instruction on using the strategies for deriving the meaning of new words

- presenting a list of unknown words at the top of the text and the students noted the list of words before reading the text

- underlying the target words as a "selective attention"

- inferring the meaning of the words in this stage

- matching columns

- doing tasks of various types including underlying, analyzing, using parts of speech, interpretation of form-meaning relationships, matching definition,

- Administering the post-test

\section{RESULTS}

\section{A. Administration and Manipulation of the PET}

The PET was administered to 150 participants in order to 1) select 100 homogeneous 2) to investigate the empirical validity of the pre-test and the post-test of vocabulary retention.

Table 1 displays the descriptive statistics for the PET. Based on the mean score of 82.01 and the standard deviation of 9.37, 100 subjects were selected to participate in the main study. That is to say, the students whose scores on the PET test fall between 72.64 and 91.38 were selected to participate. The K-R21 reliability index for the test is also .84; an acceptable index.

TABLE 1.

DESCRIPTIVE STATISTICS OF THE PET

\begin{tabular}{|c|c|c|c|c|c|c|c|c|c|}
\hline \multirow{2}{*}{$\begin{array}{l}\mathrm{N} \\
\mathrm{St} \\
\end{array}$} & \multirow{2}{*}{\multicolumn{2}{|c|}{$\begin{array}{l}\text { Mean } \\
\text { Statistic } \\
\text { Statistic }\end{array}$}} & \multirow{2}{*}{$\begin{array}{l}\text { Variance } \\
\text { Statistic }\end{array}$} & \multicolumn{2}{|c|}{ Skewness } & \multirow{2}{*}{$\begin{array}{l}\text { Normality } \\
\text { Test }\end{array}$} & \multicolumn{2}{|c|}{ Kurtosis } & Normality \\
\hline & & & & Statistic & Std. Error & & Statistic & Std. Error & Test \\
\hline PET $150 \mid 150$ & 82.01 & 9.37 & 87.79 & -.15 & 1.19 & -.77 & .67 & .49 & 1.35 \\
\hline
\end{tabular}

\section{B. Test Normalization}

To show the normality of the pre-test and the post-test on two experimental groups, the data from both groups on the pre-test and post-test presented respectively in tables 2 and 3 show that the tests enjoy normal distributions. The ratios of skewness and kurtosis are with $+/-1.96$, meaning that none of the ratios are beyond $+/-1.96$.

TABLE 2.

DESCRIPTIVE STATISTICS AND NORMALITY OF LEXICAL INFERENCING GROUP ON THE PRE-TEST AND THE POST-TEST

\begin{tabular}{|l|l|l|l|}
\hline \multicolumn{1}{|l|}{} & PRE-TEST & POST-TEST \\
\hline \multirow{5}{*}{ Inferencing } & Mean & 28.28 & 35.83 \\
\cline { 2 - 4 } & Median & 25.89 & 36.00 \\
\cline { 2 - 4 } & Mode & 21.71 & $32.00^{\mathrm{a}}$ \\
\cline { 2 - 4 } & Std. Deviation & 7.99 & 3.48 \\
\cline { 2 - 4 } & Variance & 63.84 & 12.14 \\
\cline { 2 - 4 } & Skewness & 0.23 & -0.15 \\
\cline { 2 - 4 } & Std. Error of Skewness & 0.43 & 0.43 \\
\cline { 2 - 4 } & Normality Test of Skewness & 0.53 & -0.35 \\
\cline { 2 - 4 } & Kurtosis & -1.54 & -1.23 \\
\hline & Std. Error of Kurtosis & 0.83 & 0.83 \\
\cline { 2 - 4 } & Normality Test of Kurtosis & -1.85 & -1.47 \\
\cline { 2 - 4 } & Minimum & 16.70 & 30.00 \\
\cline { 2 - 4 } & Maximum & 40.08 & 41.00 \\
\hline
\end{tabular}


TABLE 3.

DESCRIPTIVE STATISTICS AND NORMALITY OF THE HYBRID MODEL GROUP IN THE PRE-TEST AND THE POST-TEST

\begin{tabular}{|c|l|l|l|}
\hline \multirow{5}{*}{} & Mean & 29.61 & 43.37 \\
\cline { 2 - 4 } & Median & 30.06 & 42.50 \\
\cline { 2 - 4 } & Mode & 21.71 & 42.00 \\
\cline { 2 - 4 } & Std. Deviation & 7.76 & 5.15 \\
\cline { 2 - 4 } & Variance & 60.19 & 26.52 \\
\cline { 2 - 4 } & Skewness & -0.02 & 0.43 \\
\cline { 2 - 4 } & Std. Error of Skewness & 0.43 & 0.43 \\
\cline { 2 - 4 } & Normality Test of Skewness & -0.05 & 1.00 \\
\cline { 2 - 4 } & Kurtosis & -1.26 & -0.86 \\
\cline { 2 - 4 } & Std. Error of Kurtosis & 0.83 & 0.83 \\
\cline { 2 - 4 } & Normality Test of Kurtosis & -1.51 & -1.03 \\
\cline { 2 - 4 } & Minimum & 16.70 & 35.00 \\
\cline { 2 - 4 } & Maximum & 41.75 & 53.00 \\
\hline
\end{tabular}

\section{Test Validation}

To evaluate the validity of the pre-test and the post-test, the Pearson correlation between the PET test and the pre-test and the post-test of vocabulary retention were used as the criterion validity of the latter two tests. As displayed in Table 4, the Pearson correlation coefficients between the PET test and the pre-test $(\mathrm{R}=.56: \mathrm{P}=.000<.05)$ and the post-test $(\mathrm{R}=.95: \mathrm{P}=.000<.05)$ are both acceptable indices.

TABLE 4.

VALIDITY OF THE PET AND THE PRE-TEST AND THE POST-TEST

\begin{tabular}{|l|l|c|c|}
\hline \multicolumn{2}{|l|}{} & PRE-TEST & POST-TEST \\
\hline PET & Pearson Correlation & $.569^{* *}$ & $.954^{* *}$ \\
\cline { 2 - 4 } & Sig. (2-tailed) & .000 & .000 \\
\cline { 2 - 4 } & $\mathrm{N}$ & 100 & 100 \\
\hline
\end{tabular}

\section{Pre-test of Vocabulary Retention on Hybrid Model and Inferencing Groups}

An independent t-test was run to compare the mean scores of the lexical inferencing and Hybrid Model groups on the pre-test of vocabulary retention in order to probe their entry knowledge on vocabulary prior to the treatments. As displayed in Table 5, the t-observed value on the pre-test of vocabulary retention is .65 . This amount of t-value is lower than the critical value of 2 at 58degrees of freedom.

TABLE 5.

INDEPENDENT T-TEST OF INFERENCING AND HYBRID MODEL GROUPS ON THE PRE-TEST

\begin{tabular}{|c|c|c|c|c|c|c|c|c|c|}
\hline & \multicolumn{2}{|c|}{$\begin{array}{l}\text { Levene's Test for Equality of } \\
\text { Variances }\end{array}$} & \multicolumn{7}{|c|}{ t-test for Equality of Means } \\
\hline & & & & & Sig. (2- & Mean & Std. Error & $\begin{array}{l}95 \% \\
\text { of the I }\end{array}$ & $\begin{array}{l}\text { nfidence Interval } \\
\text { fference }\end{array}$ \\
\hline & $\mathrm{F}$ & Sig. & $\mathrm{T}$ & Df & tailed) & Difference & Difference & Lower & Upper \\
\hline $\begin{array}{l}\text { Equal variances } \\
\text { assumed }\end{array}$ & .69 & .408 & 65 & 58 & .514 & 1.33 & 2.03 & -2.73 & 5.406 \\
\hline $\begin{array}{l}\text { Equal variances not } \\
\text { assumed }\end{array}$ & & & .65 & 557.95 & .514 & 1.33 & 2.03 & -2.73 & 5.406 \\
\hline
\end{tabular}

As displayed in Table 5, the Levene's statistics is not significant $(\mathrm{F}=.69: \mathrm{P}=.40>.05)$. That is why the first row of Table 5, "Equal variances assumed" is reported. Accordingly, both groups were homogenous in terms of the entry knowledge on vocabulary retention. The mean scores for the inferencing and Hybrid Model groups on the pre-test of vocabulary retention are 28.27 and 29.61, respectively. These results are shown in table 6 .

TABLE 6.

DESCRIPTIVE STATISTICS OF HYBRID MODEL AND LEXICAL INFERENCING ON THE PRE-TEST

\begin{tabular}{|l|l|l|l|l|}
\hline GROUPS & $\mathrm{N}$ & Mean & Std. Deviation & Std. Error Mean \\
\hline Hybrid Model & 30 & 29.61 & 7.75 & 1.41 \\
\hline Inferencing & 30 & 28.27 & 7.99 & 1.45 \\
\hline
\end{tabular}

\section{E. Investigation of the Research Question One}

To investigate the first research question, a paired-sample t-test was run to compare the mean scores of the lexical inferencing group on the pre-test and the post-test of vocabulary retention. As displayed in Table 7, the t-observed value is 8.68. This amount of t-value is higher than the critical value of 2.04 at 29 degrees of freedom. 
TABLE 7.

PAIRED SAMPLE T-TEST OF LEXICAL INFERENCING ON THE PRE-TEST AND THE POST-TEST

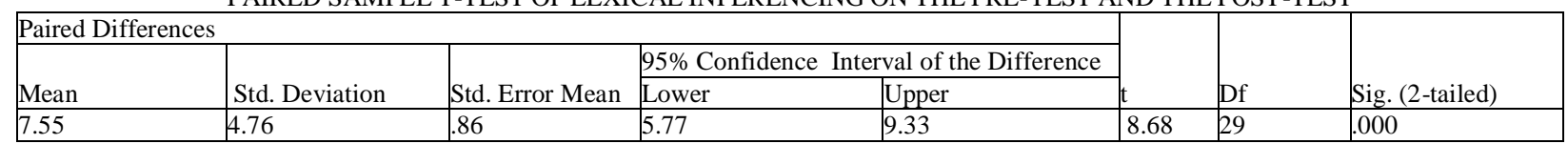

These results indicate that there is a significant difference between the mean scores of the lexical inferencing group on the pre-test and the post-test of vocabulary retention.

TABLE 8.

DESCRIPTIVE STATISTICS OF LEXICAL INFERENCING ON THE PRE-TEST AND THE POST-TEST

\begin{tabular}{|l|l|l|l|l|}
\hline & Mean & N & Std. Deviation & Std. Error Mean \\
\hline POST-TEST & 35.83 & 30 & 3.48 & .63 \\
\hline PRE-TEST & 28.27 & 30 & 7.99 & 1.45 \\
\hline
\end{tabular}

As displayed in Table 8, the lexical inferencing group performed better on the post-test of vocabulary retention with a mean score of 35.83. Thus, the first null-hypothesis as lexical inferencing does NOT have any significant effect on vocabulary retention rate is rejected.

\section{F. Investigation of the Research Question Two}

Similarly, a paired-sample t-test was run to compare the mean scores of the Hybrid Model group on the pre-test and the post-test of vocabulary retention. As displayed in Table 9, the t-observed value is 17.18. This amount of $t$-value is higher than the critical value of 2.04 at 29 degrees of freedom.

TABLE 9.

PAIRED-SAMPLES T-TEST OF HYBRID MODEL ON THE PRE-TEST AND THE POST- TEST

\begin{tabular}{|c|c|c|c|c|c|c|c|}
\hline \multicolumn{5}{|c|}{ Paired Differences } & \multirow[b]{3}{*}{ t } & \multirow[b]{3}{*}{$\mathrm{df}$} & \multirow[b]{3}{*}{ Sig. (2-tailed) } \\
\hline \multirow[b]{2}{*}{ Mean } & \multirow[b]{2}{*}{ Std. Deviation } & \multirow[b]{2}{*}{ Std. Error Mean } & \multicolumn{2}{|c|}{$95 \%$ Confidence Interval of the Difference } & & & \\
\hline & & & Lower & Upper & & & \\
\hline 13.75 & 4.38 & 8004 & 12.11 & 15.38 & 17.180 & 29 & .000 \\
\hline
\end{tabular}

Then, there is a significant difference between the mean scores of the Hybrid Model group on the pre-test and the post-test of vocabulary retention. As displayed in Table 10, the Hybrid Model group performed better on the post-test of vocabulary retention with a mean score of 43.36. Thus, the second null-hypothesis as the Hybrid Model does NOT have any significant effect on vocabulary retention rate is rejected.

TABLE 10 .

DESCRIPTIVE ST ATISTICS OF THE HYBRID MODEL ON THE PRE-TEST AND THE POST-TEST
\begin{tabular}{|l|l|l|l|l|}
\hline & Mean & N & Std. Deviation & Std. Error Mean \\
\hline POST-TEST & 43.36 & 30 & 5.14 & .94 \\
\hline PRE-TEST & 29.61 & 30 & 7.75 & 1.41 \\
\hline
\end{tabular}

\section{G. Investigation of the Research Question Three}

The third research question was investigated running an independent t-test to compare the mean scores of both groups on the post-test of vocabulary retention in order to probe the achievements. As displayed in Table 11, the tobserved value of the two groups' mean scores on the post- test of vocabulary retention is 6.63. This amount of t-value is higher than the critical value of 2.66 at 58 degrees of freedom for .01 levels of significance. So, there is a significant difference between the lexical inferencing and the Hybrid Model groups' mean scores on the post-test of vocabulary retention.

TABLE 11.

INDEPENDENT T-TEST OF LEXICAL INFERENCING AND HYBRID MODEL ON THE POST-TEST

\begin{tabular}{|c|c|c|c|c|c|c|c|c|c|}
\hline & $\begin{array}{l}\text { Leven } \\
\text { of Var }\end{array}$ & Equality & t-test $\mathrm{f}$ & r Equa & y of Means & & & & \\
\hline & & & & & & Mean & Std. Error & $\begin{array}{l}95 \% \mathrm{C} \\
\text { the Dif }\end{array}$ & nce Interval of \\
\hline & F & Sig. & $\mathrm{T}$ & Df & (2-tailed) & Difference & Difference & Lower & Upper \\
\hline Equal variances assumed & 4.640 & .035 & 6.636 & 58 & .000 & 7.53 & 1.13 & 5.26 & 9.80 \\
\hline Equal variances not assumed & & & 6.636 & .957 & .000 & 7.53 & 1.13 & 5.25 & 9.81 \\
\hline
\end{tabular}

The mean scores for both groups on the post-test of vocabulary retention are 35.83 and 43.36, respectively. The Hybrid Model group performed better on the post-test of vocabulary retention. The results of comparison of mean scores between the Hybrid Model and lexical inferencing are presented in table 12. 
TABLE 12

DESCRIPTIVE STATISTICS OF LEXICAL INFERENCING AND HYBRID MODEL ON THE POST-TEST

\begin{tabular}{|l|l|l|l|l|}
\hline Groups & $\mathrm{n}$ & mean & Std. Deviation & Std. Error mean \\
\hline Hybrid model & 30 & 43.3667 & 5.14938 & .94014 \\
\hline inferencing & 30 & 35.8333 & 3.48478 & .63623 \\
\hline
\end{tabular}

It should be noted that two groups do not enjoy homogenous variances on the post-test of vocabulary retention - an assumption that must be met for an appropriate independent t-test analysis. As displayed in Table 12, the Levene's statistics is significant $(\mathrm{F}=4.64: \mathrm{P}=.035<.05)$. That is why the level of significance is reduced from .05 to .01 when calculating the critical t-value mentioned above.Thus, the third null-hypothesis as the hybrid Model is NOT more effective than lexical inferencing in vocabulary retention rate is rejected.

\section{DISCUSSION}

Nelson and Stage (2007) studied about the effect of contextually-based multiple meaning vocabulary instruction on the vocabulary knowledge and reading comprehension. Their work was a kind of map very similar to the model defended in this study. They concluded that their strategy had a significant effect on their participants. The findings of this study were closely related to Nelson and Stage. Furthermore, Boxtel, Linden, Roelofs, Erkens (2002) proved concept mapping as a collaborative strategy is a useful tool to provoke such student interaction as sustained by this study.

Monroe (1997) investigated the effect of "definition -only model" and "CD - model" on mathematical vocabulary of forth grade students. CD- frayer model is a combination of "concept definition map" and "frayer model". She (1997) found that CD-frayer model was more effective because the students used more mathematical vocabulary in their writing. Stahl and Clark (1987) used a kind of semantic mapping. The results of their study revealed that students' participation is an important factor in vocabulary learning. So, this study can prove the collaborative nature of graphic organizers.

On the other hand, different studies tried to examine the effect of lexical inferencing on vocabulary learning and each of them probed it from different dimensions. The findings of this study contrasted with Chodkiewicz's (2001) findings, who studied about the vocabulary acquisition through different reading comprehension tasks. She found that medium and high proficient student profited more than low proficient ones and they gained more vocabulary than the weak students through reading tasks.

In castrate with Chodkiewicz (2001), Fraser (1999) indicated that reading for comprehension can be productive for incidental vocabulary learning and the students used more productive lexical strategies like consulting and inferencing than unproductive strategies when encounter the new words. The students could determine the adequate meaning of new words through inferencing and consulting, but they utilized cues of text during inferencing. Fraser (1999) also found that instruction for enhancing lexical processing had rather indirect effect on vocabulary learning. Fraser (1999) also concluded that the reading proficiency level did not affect on retention of new words' meanings and the retention rate of self -selected words by students is higher than the other words. Similarly, Vasiljevic (2008) concluded that lexical inferencing was not as effective as other considered strategies. According to Valsiljevic (2008) Inferring word meaning from context was behind the other models in both productive and receptive uses of the target words, with the impact in productive use being more pronounced. In fact the result of this study verifies the use of reading plus as the strategy of lexical inferencing as Vasiljevic's (2008) findings did because lexical inferencing results were lower in comparison with those of the Hybrid Model one.

Paribakht and Wesche (1997) indicated that lexical inferencing can lead to recognize a large amount of words from text but it does not guarantee the development of complex knowledge of new learnt words. Thus, they (2000) used reading plus strategy which caused increasing elaboration and strengthening of different dimensions of word knowledge. Their study also revealed that text-based vocabulary exercises accompanied by a reading text can promote learning particular words and their lexical features.

Min (2008) also verified Paribakht and Wesche's (2000) findings since he found that reading plus is more effective and efficient than narrow reading in vocabulary learning and retention. Findings on lexical inferencing strategy in this study, was exactly in line with Paribakht and Wesche (2000), and Min (2008). All of them followed the same procedures and gained the same results that showed the effectiveness of lexical inferencing strategy through reading plus.

\section{CONCLUSION}

Both of these strategies were in the continuum of incidental and intentional learning. In other words, both of them take the benefits of inferring during the reading phase and the students may incidentally learn or guess the meaning of the words, or they may find information that helps them to recognize the meaning of the words, but every strategy follows a various route for learning the new words. The result of study indicated that both strategies significantly lead to better vocabulary retention but the students who participated in the Hybrid Model instruction gained better results in the light of its more collaborative, mathematical, interactive, productive, autonomous training, flexible and innovative nature among many other features. Pedagogically speaking, teachers can use the Hybrid Model without limitations of other graphic organizers, it enjoys more productive nature required for promoting vocabulary knowledge, and entails inde- 
pendent learning contrary to the lexical inferencing model which necessitates teachers and material designers to consider special tasks for its implementation.

\section{REFERENCES}

[1] Barcroft, J. (2004). Second language vocabulary acquisition:A lexical input processing approach. Foreign Language Annals $37.2,200-209$.

[2] Blachowicz, C., \& Fisher, P. J. (2009). Teaching vocabulary in all classrooms 4th edition. Massachusetts: Allyn \& Bacon, Inc.

[3] Bot, d., Paribakht, T., \& Wesche, M. (1997). Toward a lexical processing model for the study of second language acquisition. Studies in Second Language Acquisition 19.3, 309-329.

[4] Boxtel, C. v., Linden, J. v., Roelofs, E., \& Erkens, G. (2002). Collaborative concept mapping: Provoking and supporting meaningful discourse. THEORY INTO PRACTICE 41.1, 40-46.

[5] Chodkiewicz, H. (2001). The acquisition of word meanings while reading in English as a foreign language. EUROSLA Yearbook 1, 29-49.

[6] de Bot, K., Paribakht, S. T., \& Wesche, M. (1997). Toward a lexical processing model for the study of second language vocabulary acquisition:Evidence from ESL reading. Studies in Second Language Acquisition 19 .3 , 309-329.

[7] Ellis, N. C. (2005). At the interface:Dynamic interactions of explicit and inplicit language knowedge. Studies in Second Language Acquisition 27 .2, 305-353.

[8] Eppler, M. J. (2006). A Comparison between Concept Maps, Mind Maps, Conceptual Diagrams, and Visual Metaphors as Complementary Tools for Knowledge Construction and Sharing. Information Visualization 5 .3, 202-210.

[9] Fraser, C. A. (1999). Lexical processing strategy use and vocabulary learning through reading. Studies for Second Language Acquisition 21, 225-241.

[10] Frayer, D. A., Fredrick Wayne, C., \& Klausmeier, H. J. (1969). A schema for testing the level of concept mastry. Madison: University of Wisconsin.

[11] Fukkink, R., \& Glopper, K. d. (1998). Effects of instruction in deriving word meaning from context: A meta-analysis. Review of Educational Research 68 .4, 450-469.

[12] Gouveia, L. B. (2004). A brief survey on cognitive maps as humane representation. Proto: Universidade Fernando Pessoa. CEREM.

[13] Greenwood, S. C. (2002). Making words matter:Vocabulary study in content area. The Clearing House 75 .5, 258-264.

[14] Guo, Y. (2010). L2 vocabulary acquisition through reading -incidental learning and intentional learning. Chinese Journal of Applied Linguistis .(Bimonthly) 33.1, 74-94.

[15] Harmon, J. M. (1998). Vocabulary teaching and learning in a seventh-grade literature-based classroom. Journal of Adolescent \& Adult Literacy 41.7, 518-529.

[16] Hulstijn, J. H., Hollander, M., \& Greidanus, T. (1996). Incidental vocabulary learning by advanced foreign language learners: The influence of mariginal glosses, dictionary use, and reoccurrence. The Modern Language Journal 80 .3, 327-339.

[17] Klausmcier, H. J., \& Voerwerk Feldman, K. (1975). Effects of a definition and a varying number of examples and nonexamples on concept attainment. Journal of Educational Psychology 67.2, 174-178.

[18] Krasen, S. (1989). Additional Evidence for the Input Processing. The Modern Language Journal 73.4, 440-464.

[19] Kuhn, M. R., \& Stahl, S. A. (1998). Teaching children to learn word meanings from context: A synthesis and some questions'. Journal of Literacy Research 30, 119-138.

[20] Laufer, B. (2009). Second language vocabulary acquisition from language input and from form- focused activities. Language Teaching 42.3, 341-354.

[21] Laufer, B., \& Hulstijn, J. (2001a). Incidental vocabulary acquisition in a second language:The construct of task-induced involvement. Applied Linguistic 22 .1, 1-26.

[22] Min, H.-T. (2008). EFL Vocabulary Acquisition and Retention:Reading Plus Vocabulary Enhancement Activities and Narrow Reading. Language Learning 58.1, 73-115.

[23] Monroe, E. E. (1997). Effects of mathematical vocabulary instruction on fourth grade students. 34.3,. Reading Improvement $34.3,120-32$.

[24] Nagy, W. E., Herman, P. A., \& Anderson, R. C. (1985). Learning words from context. Reading Research Quarterly 20.2 , $233-$ 253.

[25] Nassaji, H. (2006). The Relationship between Depth of Vocabulary Knowledge and L2 Learners' lexical Inferencing Strategy Use and Success. Modern Language Journal 90.3, 387-401.

[26] Nation, I. (2001). Learning vocabulary in another language. Cambridge: Cambridge University Press.

[27] Nelson, J. R., \& Stage, S. A. (2007). Fostering the Development of Vocabulary Knowledge and Reading Comprehension Though Contextually-Based Multiple Meaning Vocabulary Instruction. Education and Treatment of Children 30.1, 1-22.

[28] Nesbit, J. C., \& Adesope, O. O. (2006). Learning with concept and knowledge maps:A Meta-Analysis. Review of Educational Reseach 76.3, 413-448.

[29] NICHD. (2000). Report of the national reading panel:Teaching children to read reports of the subgroups U.S. National Institute of Health, Department of Health and Human Services. Washington DC: NIH Publication.

[30] Paribakht, T., \& Wesche, M. (1997). Vocabulary enhancement activities and reading for meaning in second language vocabulary development. In T. N. James Coady, Second language vocabulary acquisition: a rationale for pedagogy, 174-200. New York: Cambridge University Press.

[31] Pikulski, J. J., \& Templeton, S. (2004). Teaching and developing vocabulary: Key to long-term reading success. Houghton Mifflin Company, 1-12.

[32] Pulido, D. (2007). The Effects of topic familiarity and passage sight vocabulary on L2 lexical inferencing and retention through reading. Applied Linguistics 28.1, 66-86.

[33] Reider, A. (2003). Implicit and Explicit Learning in Incidental Vocabulary Acquisition. Vien: EUROSLA. 
[34] Rosenbaum, C. (2001). A word map for middle school: A tool for effective vocabulary instruction. Journal of Adolescent \& Adult Literacy 45.1, 44-50.

[35] Rupley, W. H., \& Nichols, W. D. (2006). Vocabulary instruction for the struggling reader. Reading \& Writing Quarterly 21.3,239-260.

[36] Schmitt, N. (2008). Review article: Instructed second language vocabulary learning. Language Teaching Research 12.3 , 329 363.

[37] Schouten Van- Parreren, C. (1989). Vocabulary learning through reading: Which conditions should be met when presentin words in texts? AILA Review 6, 75-85..

[38] Schwartz, R. M., \& Raphael, T. E. (1985). Concept of definition: A key to improving students' vocabulary. The Reading Teacher 39.2, 198-205.

[39] Sedita, J. (2005). Effective vocabulary instruction. Insights on Learning Disabilities 2.1, 33-45.

[40] Stahl, S. A., \& Clark, C. H. (1987). The Effects of Participatory Expectations in Classroom Discussion on the Learning of Science Vocabulay. American Educational Research Journal 24.4, 541-555.

[41] Stahl, S. A., \& Shiel, T. G. (1992). Teaching meaning vocabulary:Productive approaches for poor readers. Reading and Writing Quarterly: Overcoming Learning Difficulties 8.2, 223-241.

[42] Svenconis, D. J., \& Kerst, S. (1995). Investigating the teaching of second language vocabulary through semantic mapping in hyper text enviroment. CALICO 12.2\&3, 33-57.

[43] Takač, V. P. (2008). Vocabulary Learning Strategies and Foreign Language Acquisition. United Kingdom: Channel View Publications Ltd.

[44] Taylor, B. D., Mraz, M., Nichols, W. D., Rickelman, R. J., \& and Wood, K. (2009). Using Explicit Instruction to Promote Vocabulary Learning for Struggling Readers. Reading \& Writing Quarterly 25 .2, 205-220.

[45] Tumolo, C. H. (2007). Vocabulary and reading: teaching procedures in the ESP classroom. Linguagem \& Ensino 10.3, 477-502.

[46] Vasiljevic, Z. (2008). Teaching Vocabulary to Advanced Japanese Students: A Word Association Approach. The East Asian Learner 4.1, 1-19.

[47] Wesche, M. B., \& Paribakht, T. S. (2000). Reading-Based exercises in second language vocabulary learning: An introspective study. The Modern Language Journal 84.2, 196-213.

Gholam-Reza Abbasian, assistant professor of TEFL at Imam Ali and Islamic Azad (South Tehran Branch) universities. He has presented at a good number of both national and international conferences. He is also the author of five books and has translated at least ten others. Furthermore, he has published several scholarly articles in national and international academic journals.

Banafsheh Arianezhad holds an M.A. in TEFL from Islamic Azad University, Garmsar Branch, Iran. She is involved in teaching English at various English language schools and institutes. She is also more interested in doing research in the area of teaching vocabulary, reading and test preparation. 